Research Article

\title{
Research on Friction Stir Spot Welding Brazing Process and Properties of Dissimilar Metals DP590 and 6061
}

\author{
Kai Xu $\mathbb{1 D}^{1}$ and Shu-quan Zhang ${ }^{2}$ \\ ${ }^{1}$ School of Aeronautic and Materials, Anhui Technical College of Mechanical and Electrical Engineering, Wuhu 241000, China \\ ${ }^{2}$ Institute of Plasma Physics, Chinese Academy of Sciences, Hefei 341000, China \\ Correspondence should be addressed to Kai Xu; xk@ahcme.edu.cn
}

Received 28 February 2020; Revised 12 May 2020; Accepted 25 May 2020; Published 17 June 2020

Academic Editor: Pavel Lejcek

Copyright ( $2020 \mathrm{Kai}$ Xu and Shu-quan Zhang. This is an open access article distributed under the Creative Commons Attribution License, which permits unrestricted use, distribution, and reproduction in any medium, provided the original work is properly cited.

\begin{abstract}
Friction stir welding (FSW) is the most popular and efficient method for solid-state joining of similar or dissimilar metals and alloys. This technology is mostly applied in aerospace, rail, automotive, and marine industries. In order to reduce the weight of special auto parts, friction stir spot welding (FSSW) was proposed by some researchers for the connection of steel-aluminium dissimilar metals. However, the steel-aluminium joints welded by FSSW are prone to brittle fracture and have lower shear load although they have high mechanical connection strength. The friction stir spot welding brazing process integrates the brazing effects with the friction welding effects by the addition of solder. A study of FSSW of DP590 and 6061 with the filler metal added was carried out in this paper. The orthogonal test was performed to optimize the process parameters in order to achieve the best shear load of the joint. The shear strength of the joint was studied by the shear test. The fracture morphology was investigated by optical microscopy (OM), scanning electron microscope (SEM), and energy dispersive spectrometer (EDS). The results showed that the shear load of the joint could reach $13.239 \mathrm{kN}$ when the rotating speed, depth, and residence time of the mixing head were $1000 \mathrm{r} / \mathrm{min}, 0.2 \mathrm{~mm}$, and $90 \mathrm{~s}$, respectively. The aluminium-zinc solder added could well wet the interface between aluminium and steel and promote the metallurgical bonding, thereby improving the shear load of the joint. The temperature field of DP590/6061 FSSW process was simulated by ANSYS software to verify the rationality of the optimal process parameters. The simulation results were confirmed to be basically consistent with the data measured by the thermocouple.
\end{abstract}

\section{Introduction}

Aluminium alloy has small density, high specific strength, good conductivity, and corrosion resistance. The dual-phase high-strength steel is known for its high strength, high initial work hardening rate, and good anticollision performance $[1,2]$. The hybrid structure of aluminium alloy and highstrength steel is recognized as the ideal material for lightweight, energy-saving, and environmentally friendly vehicles, and it has been applied in some high-end vehicles at home and abroad [3-8]. However, the molten aluminium and steel are likely to form the brittle intermetallic compounds due to the low solid solubility between these two materials, which will reduce the mechanical properties of the joint $[9,10]$. Besides, distinct thermal physical properties of the two materials can easily lead to internal stress generation and assembly failure during welding $[11,12]$. Research has been carried out to seek processes for producing highquality joints, and a great deal is about friction stir welding of dissimilar materials. Ruxing et al. studied the influence of welding process parameters on the shear resistance of welded joints through experiments on tapping, stirring, and friction spot welding of $2 \mathrm{~mm} \mathrm{L2024}$ aluminium alloy and $4 \mathrm{~mm}$ low-carbon steel [13]. Rajendran et al. investigated the strength and microstructural characteristics of friction stir welded lap joints of AA2014-T6 aluminium alloy [14-16]. Wang Xijing et al. researched on keyless FSSW of $3 \mathrm{~mm}$ 6061-T6 deformed aluminium alloy and $1 \mathrm{~mm}$ DP600 galvanized steel plate [17]. The weldability of aluminium alloy was analyzed by the orthogonal test with the equipment of 
back drawing FSSW [18-22]. The steel-aluminium joint prepared by the abovementioned spot welding modes has high mechanical connection strength since it is connected by the friction heat $[23,24]$, but it also has some shortcomings. For example, brittle fracture easily occurs, the shear load of joint is low in most cases, and the stirring head is prone to wear [25-29]. The fracture mechanism is also unclear. The friction stir spot welding brazing of steel and aluminium integrates the brazing and friction welding of the two types of metals by the addition of solder, capable of reducing the wear of the mixing head. Therefore, a series of experiments on the friction stir spot welding brazing process of steel and aluminium with filler material added were carried out in this paper. The FSSW brazing method was used for lap weld of two dissimilar metals, i.e., DP590 steel and 6061 aluminium alloy. The parameters of FSSW process with solder added were optimized by the orthogonal test. The mechanical properties of the joint were studied by the shear test, and the fracture morphology of the joint was analyzed by OM, SEM, and EDS. The fracture form and mechanism were also discussed in this paper. Simulation was carried out using ANSYS finite element software under the optimal welding process parameters obtained by the orthogonal test to verify the rationality of the parameters.

\section{Materials and Methods}

2.1. Materials. $1 \mathrm{~mm}$ thick DP590 dual-phase steel and $2 \mathrm{~mm}$ thick 6061 aluminium alloy were subjected to FSSW. The size of both materials was $150 \mathrm{~mm} \times 100 \mathrm{~mm}$. The chemical composition of the test materials is shown in Table 1. The bottom of the steel sheet was connected to the top of the aluminium sheet to form the lap joint. The aluminium-zinc solder sheet and paste brazing flux were placed between the steel sheet and the aluminium sheet in advance, with the brazing flux under the solder. The lap joint is $50 \mathrm{~mm}$-long (Figures 1(a) and 1(b)). The equipment used in the test is the double beam gantry friction stir welding system (model: FSW-2SLM-BF0360) manufactured by Beijing FSW Technology Co., Ltd. The mixing head adopted is made of $\mathrm{H} 13$ steel (Figure 2), with a shoulder diameter of $28 \mathrm{~mm}$. The mixing needle has a diameter of $2 \mathrm{~mm}$ and a length of $0.3 \mathrm{~mm}$.

2.2. Welding Methods. Before the test, the aluminium sheet and the steel sheet were grinded with a grinder and sandpaper, respectively, and both materials were then cleaned with acetone. During welding, the mixing head was slowly pressed down until its end contacted with the upper surface of the steel sheet. Then, the mixing head end was cooled by compressed air, and meanwhile, the mixing head rotating at high speed was pressed down while rubbing. After reaching a certain depth, the mixing head kept staying at this position for a period of time until the mixing head and welding area turned red and lasted for certain time, and the welding was ended.

The orthogonal test method was used to optimize the rotating speed of the mixing head, the residence time, and the pressing depth of the mixing head. The residence time refers to the time period from the beginning of rubbing the workpiece by the mixing head end to the beginning of retreat of the mixing head. The pressing depth of the mixing head should not be too large so as to avoid the rapid wear of the mixing head due to the high hardness and strength of the steel. The orthogonal experiment of three factors and three levels designed according to the standard of the $L_{9}\left(3^{4}\right)$ orthogonal table only requires 9 tests to be conducted in theory, but three samples were actually welded under each set of welding parameters obtained by the orthogonal test for the accuracy of the shear load test. After welding, the universal testing machine was used to test the shear load of all the samples, and the average value was taken. According to the orthogonal test and shear load test results, the fracture morphology of three representative joints was studied by OM, SEM, and EDS. Table 2 shows the three factors and three levels selected based on the previous welding process test with no solder added.

2.3. Simulation Verification. The temperature field in the welding process of the DP590/6061 joint was simulated under the best process parameters obtained in the above experiments using ANSYS finite element software, so as to verify the rationality of the process parameters. Meanwhile, the thermocouple temperature measurement experiments were carried out, which were compared with the simulation results.

\section{Results and Discussion}

3.1. Shear Performance. The orthogonal test results are shown in Table 3. For example, the shear load of the $1 \#$ sample joint could reach $9.982 \mathrm{kN}$ when the rotating speed of the mixing head was $1000 \mathrm{r} / \mathrm{min}$, the depth of the mixing head was $0.1 \mathrm{~mm}$, and the residence time was $60 \mathrm{~s}$. It can be seen that the 2\# sample has the maximum shear load $(13.239 \mathrm{kN})$ when the rotating speed of the mixing head is $1000 \mathrm{r} / \mathrm{min}$, the pressing depth of the mixing head is $0.2 \mathrm{~mm}$, and the residence time is $90 \mathrm{~s}$. In contrast, the highest shear strength of the samples with no solder added is about $10 \mathrm{kN}$. Therefore, it can be concluded that the shear strength of welded joints is greatly improved by solder. The influence of different factors on the shear load was studied by the range analysis. According to Table $3, R_{\mathrm{A}}=3.285>R_{\mathrm{B}}=1.603>R_{\mathrm{C}}=0.882$, indicating that the rotating speed of the mixing head has the greatest influence on the shear load of the joint, followed by the residence time and the pressing depth of the mixing head successively.

Note that $R_{\mathrm{A}}, R_{\mathrm{B}}$, and $R_{\mathrm{C}}$ are the ranges of factors in the columns $\mathrm{A}, \mathrm{B}$, and $\mathrm{C}$, respectively. That range is the difference between the maximum and the minimum values of the average index value of each factor under each level. A larger $R_{\mathrm{A}}$ indicates a greater impact of the corresponding factor on the test indicators, so $R_{\mathrm{A}}$ is the most important.

3.2. Welding Sample. The welding sample (Figure 3) was processed by wire cutting before the shear test. The weld 
TABLe 1: Chemical composition of materials (mass fraction, \%).

\begin{tabular}{lcccccccc}
\hline Category & $\mathrm{C}$ & $\mathrm{Mn}$ & $\mathrm{Si}$ & $\mathrm{Mg}$ & $\mathrm{Zn}$ & $\mathrm{Cu}$ & $\mathrm{Al}$ \\
\hline DP590 & 0.035 & 0.174 & 0.045 & - & - & 0.006 & 0.04 & Margin \\
6061 & - & 0.15 & $0.4-0.8$ & $0.8-1.2$ & 0.25 & $0.15-0.40$ & Margin & 0.7 \\
Al-Zn solder & - & - & - & - & 88 & - & 12 \\
\hline
\end{tabular}

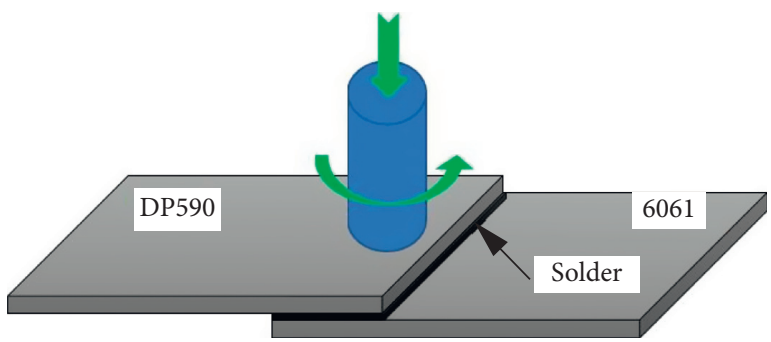

(a)

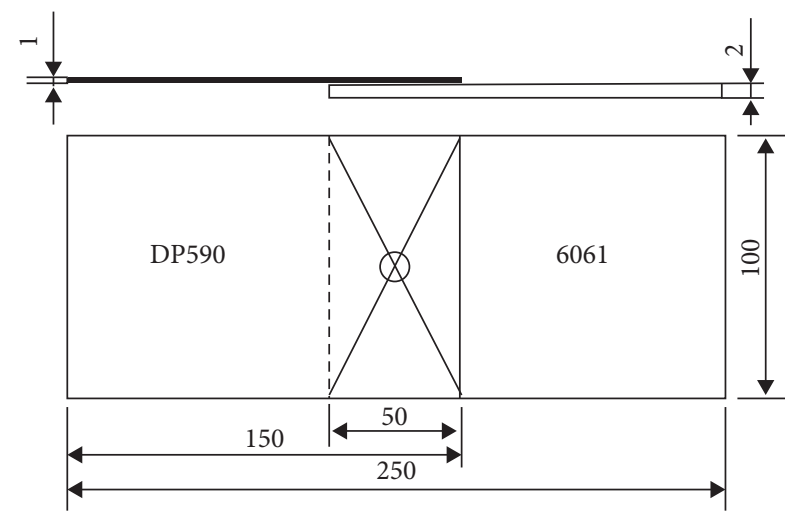

(b)

FIgURE 1: Welding joint scheme. (a) Lap joint. (b) The size of the lap joint.

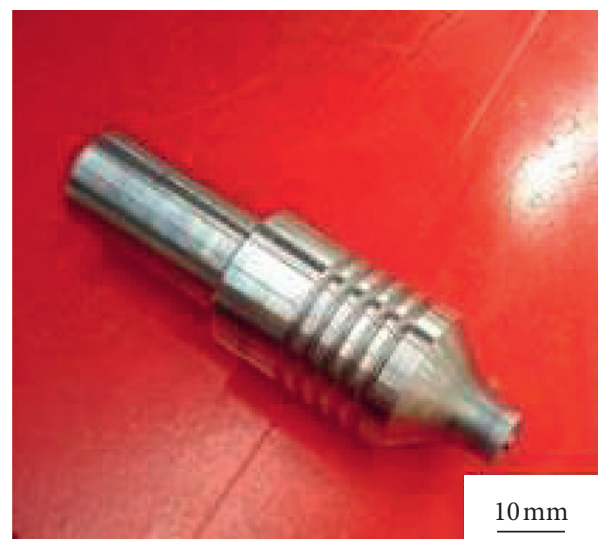

Figure 2: Mixing tool.

TABLe 2: Three factors and three levels selected in the orthogonal test.

\begin{tabular}{lccc}
\hline & & Factor & \\
Level & A & B & C \\
& Rotating speed (r/min) & Residence time (s) & Pressing depth (mm) \\
\hline 1 & 1000 & 60 & 0.1 \\
2 & 1200 & 90 & 0.2 \\
3 & 1500 & 120 & 0.3 \\
\hline
\end{tabular}

seam is divided into four areas, which are base materials, the joint zone, the heat-affected zone (HAZ), and the thermomechanically affected zone (TMAZ). Fine equiaxed recrystallization structure was formed in the joint zone owing to the severe deformation and friction heat. The TMAZ experienced plastic deformation, but no recrystallization was formed due to the lack of enough stress. The occurrence of solubilization and coarsening of the strengthening phase in 
TABLE 3: Joint shear load.

\begin{tabular}{|c|c|c|c|c|}
\hline Sample number & Rotating speed (r/min) & Residence time (s) & Pressing depth $(\mathrm{mm})$ & Shear load $(\mathrm{kN})$ \\
\hline $1 \#$ & 1000 & 60 & 0.1 & 9.982 \\
\hline 2\# & 1000 & 90 & 0.2 & 13.239 \\
\hline $3 \#$ & 1000 & 120 & 0.3 & 8.600 \\
\hline $4 \#$ & 1200 & 60 & 0.2 & 6.681 \\
\hline $5 \#$ & 1200 & 90 & 0.3 & 7.451 \\
\hline 6\# & 1200 & 120 & 0.1 & 7.835 \\
\hline 7\# & 1500 & 60 & 0.3 & 10.810 \\
\hline $8 \#$ & 1500 & 90 & 0.2 & 8.959 \\
\hline 9\# & 1500 & 120 & 0.1 & 8.415 \\
\hline Range & $R_{\mathrm{A}}=3.285$ & $R_{\mathrm{B}}=1.603$ & $R_{\mathrm{C}}=0.882$ & - \\
\hline Analysis & \multicolumn{4}{|c|}{$R_{\mathrm{A}}>R_{\mathrm{B}}>\mathrm{R}_{\mathrm{C}}$} \\
\hline
\end{tabular}

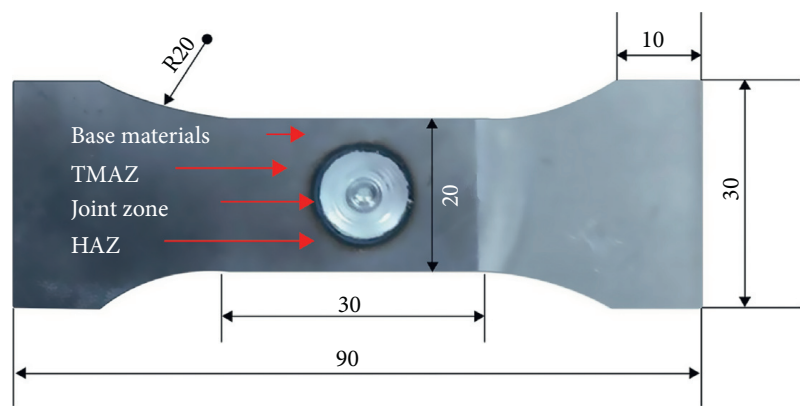

FIGURE 3: Macrograph of the welding sample.

the TMAZ was dependant on the intensity of thermal cycle experienced in this zone. The HAZ was only affected by heat and had the same grain structure as the base metals. Grains in HAZ grew greatly, and the strengthening phase coarsened under the influence of heating.

3.3. Macroscopic Morphology of Shear Fracture. The fracture morphology of three typical shear fracture samples (1\#, 2\#, and 3\#) is shown in Figure 4. It could be seen that the steel sheet and aluminium sheet were separated in the fracture of sample 1\#. The welding spot of the steel sheet was concave, part of the steel sheet adhered to the aluminium sheet, and the fracture position was mainly distributed in the mixing area. However, the steel sheet surface of sample 2\# was smooth and concave, and the crescent shaped fracture was formed in the middle of the solder joint, suggesting that large plastic deformation occurred to the joint at fracture. The steel sheet of sample $3 \#$ was completely separated from its aluminium sheet from the edge of the solder joint, and the metal in the mixing area was almost all adhered to the aluminium sheet. The fracture mainly occurred around the mixing area.

3.4. Metallographic Structure. The metallographic microstructure of sample 2\# was analyzed using an OLYMPUS BX51M metallographic microscope. It was found that the microstructure of the joint nugget area after welding was relatively small and uniform (Figure 5). The materials in the joint area reached the plastic state during welding. The plastic materials were mixed and stirred along the vertical direction of the weld seam, and they bore huge upset pressure at the same time, making the recrystallized grains unable to grow and facilitating the formation of equiaxed and fine grains (Figure 5(b)). Besides, the wetted melted solder and the galvanized layer of the steel sheet spread between steel and aluminium and filled the gap between the two metals through capillary flow and finally were metallurgically combined with the base metals (Figure 5(a)). According to the figure, the flow velocity of materials in different parts is different. Generally speaking, the flow velocity near the centre of the nugget area is smaller than that far away from the nugget area, and the material flow velocity in TMAZ is the largest.

3.5. Micromorphology Observation with SEM. The steel-aluminium joint welded by FSSW without the filler metal added in the previous test was easy to tear from the area around the mixing zone, which produced plastic deformation on the macro level, leading to adhesion between the upper and lower sheets, and even the generation of holes on one of the sheets. At this time, the joint was connected mechanically rather than metallurgically. The shear load of joints without solder added was generally low, ranging from $5 \mathrm{kN}$ to $10 \mathrm{kN}$, while the FSSW joint with the filler metal added usually broke directly at the joint interface when both mechanical and metallurgical connections existed at the joint. Different heat input resulted in different metallurgical degrees of the joint and varied metallographic structure. The micromorphology of the fracture area of $1 \#, 2 \#$, and $3 \#$ welding specimens with the filler metal added is shown in Figure 6, and the fracture position of each specimen is indicated by the red arrow in Figure 4 . It can be seen from Figure 6 that the fracture surface of the $1 \#$ test piece is smooth and flat, with some obvious white blocks and a small amount of dimples on it. There are a large number of small and nearly uniform dimples as well as few small lumps on the fracture surface of the $2 \#$ test piece, showing obvious plastic fracture characteristics. The fracture surface of the $3 \#$ test piece is also relatively flat, and there are some coarse lumps distributed on it. It is difficult to see the dimple morphology, which shows the obvious brittle fracture characteristics. Based on the above analysis, we concluded that the fracture types were related to the connection strength of joints. It is generally believed that there are both 


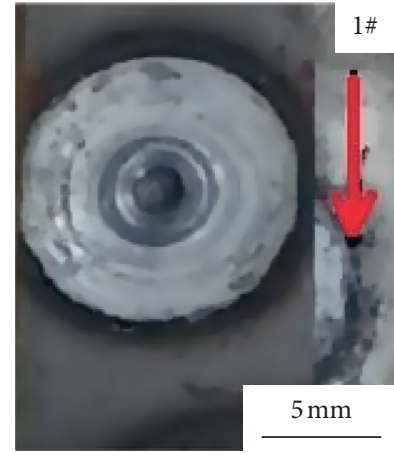

(a)

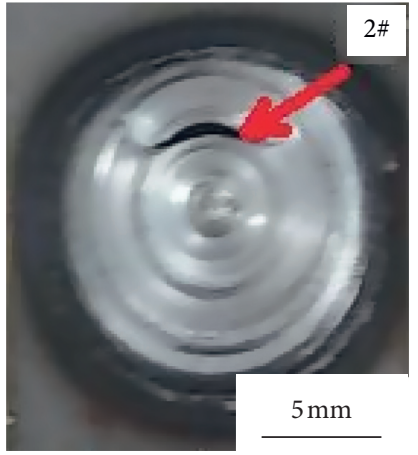

(b)

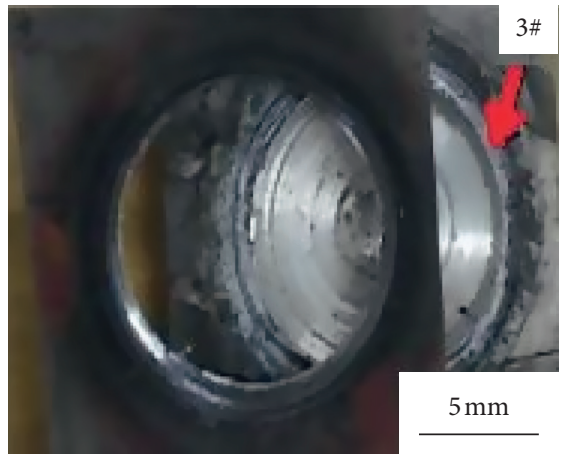

(c)

Figure 4: Fracture morphology of 1\#, 2\#, and 3\# sample joints.

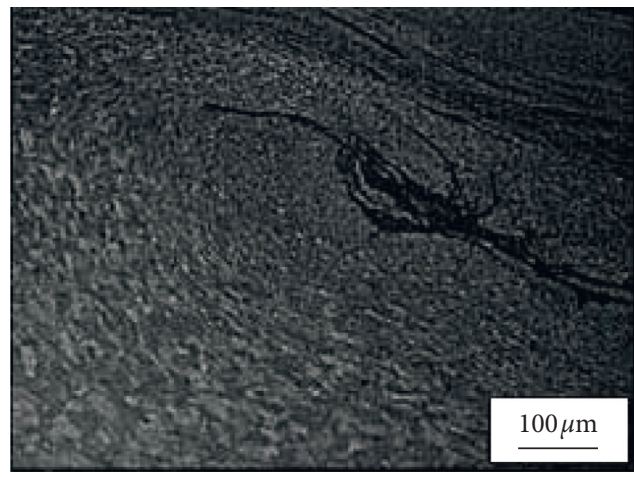

(a)

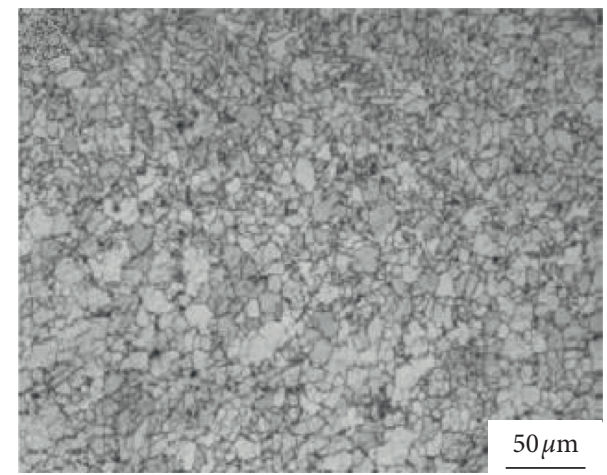

(b)

Figure 5: Microstructure of each area on two sides of the joint steel sheet. (a) Microstructure of the joint zone. (b) Microstructure of HAZ.

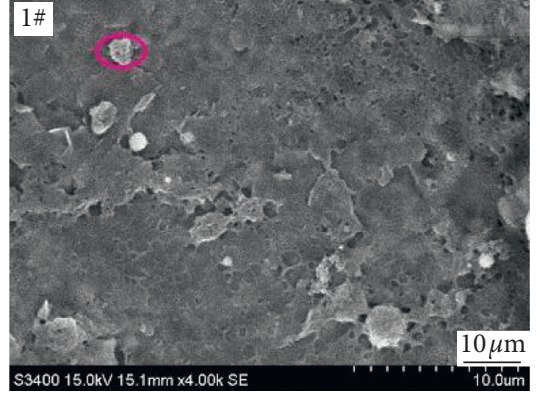

(a)

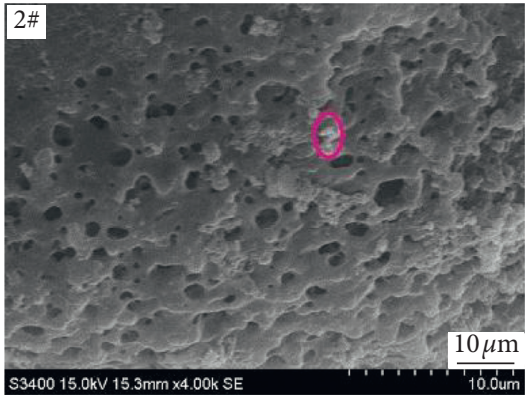

(b)

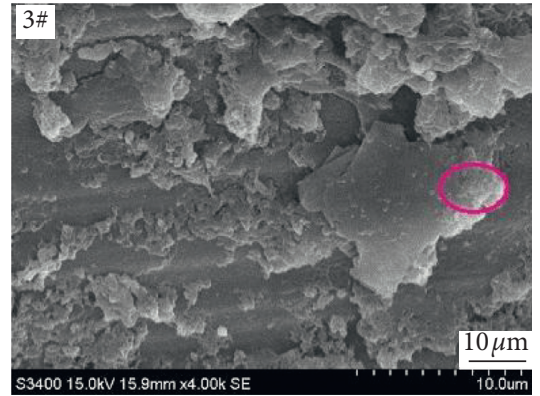

(c)

FiguRE 6: Fracture morphology observed by SEM.

plastic fracture and brittle fracture. The well connected joints will show obvious plastic fracture characteristics, while the poorly connected joints will be prone to brittle fracture.

3.6. EDS Analysis. In order to further analyze the fracture mechanism of the joint and the composition of the microstructure lump, the energy spectrum analysis of the SEM morphology of points with red circles in $1 \#, 2 \#$, and $3 \#$ samples was carried out. The energy spectrum diagram is shown in Figure 7. According to the diagram, the white lump contained not only a great deal of aluminium and zinc but also a small amount of $\mathrm{C}$ and $\mathrm{O}$, so it could be carbonates left behind by the surface film formed by aluminium alloy, $\mathrm{O}$, and $\mathrm{CO}_{2}$. The presence of this surface film increased the brittleness of the joint and reduced its shear load. The 3\# specimen had lower shear load due to the high content of the lumps, and the low content of lumps in the $2 \#$ specimen led to higher shear load. All of the three samples contained $\mathrm{Al}$ and $\mathrm{Zn}$, which indicated that the aluminium-zinc solder with a lower melting point melted first and spread out with the increase of temperature in the FSSW process. Fe existing in the $2 \#$ test piece formed compounds with 


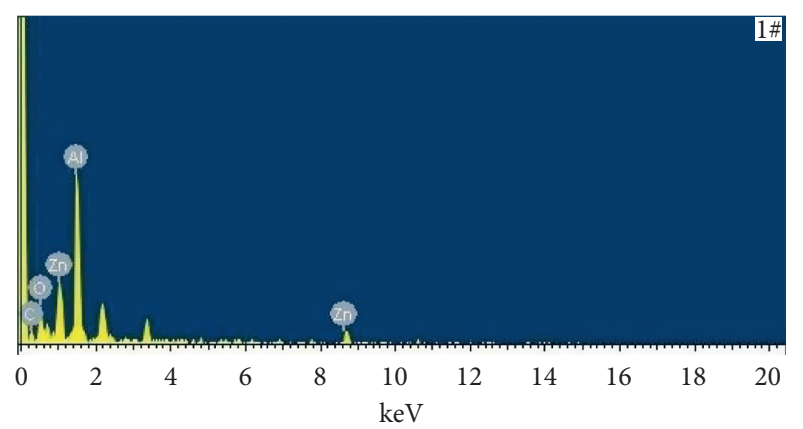

(a)

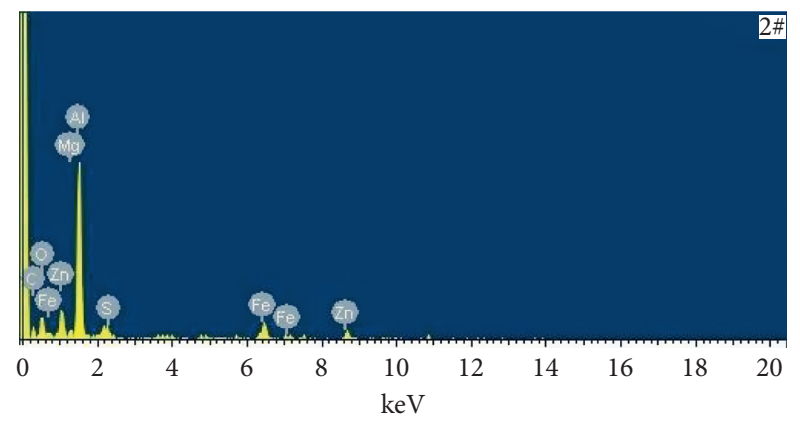

(b)

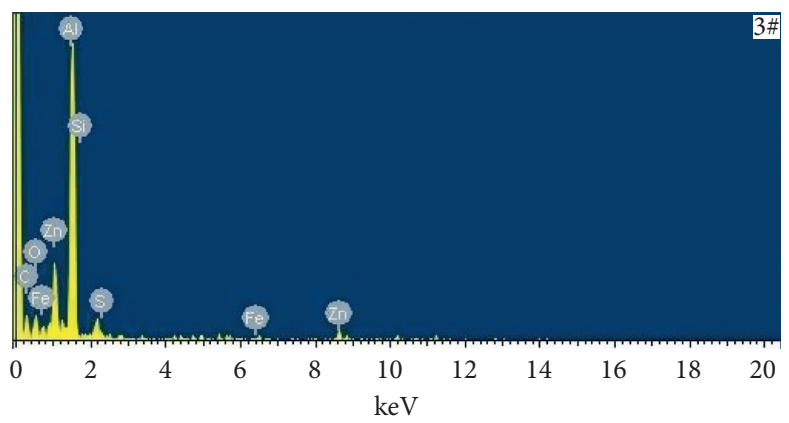

(c)

Figure 7: EDS analysis of the points circled in Figure 6.

Al. Yu Haiyang et al. believed that intermetallic compounds $\mathrm{Fe}_{2} \mathrm{Al}_{5}$ and $\mathrm{Fe}_{3} \mathrm{Al}$ formed at the interface of the joint produced the metallurgical combining force, improving the shear load of the joint [30]. It confirmed that both mechanical connection and metallurgical bonding existed at the aluminium-steel friction stir spot welding joint. Different heat input led to different metallurgic degrees of the joint, and different parameters of FSSW also brought about different joint strength. The parameter comparison showed that the rotating speed of the three test pieces was the same, but the retention time and pressing depth of the mixing head were different. Compared with the 1 \# test piece, the 2 \# test piece had longer residence time and greater pressing depth, so its heat input was relatively large and the solder diffusion was sufficient, which increased the metallurgical binding capacity of the joint. Meanwhile, the greater pressing depth facilitated the mechanical binding of the joint, improving the plasticity and shear load of the joint. The highest shear load could reach $13.239 \mathrm{kN}$. Excessive heat input due to long residence time and large pressing depth of the mixing head resulted in coarse massive structure in sample 3\# (Figure 6), making the joint brittle and easy to form brittle phase. Therefore, the shear load of sample 3\# was low.

\section{Simulation Analysis Based on ANSYS}

The geometric model of steel DP590 and aluminium alloy 6061 adopting the same joint form, size, and test parameters was established (Figure 8) [31,32]. The heat source model is shown in Figure 9 [33-36].

When the rotating speed of the mixing head is $1000 \mathrm{r} / \mathrm{min}$, the pressing depth is $0.2 \mathrm{~mm}$, and the dwell time is 60 seconds

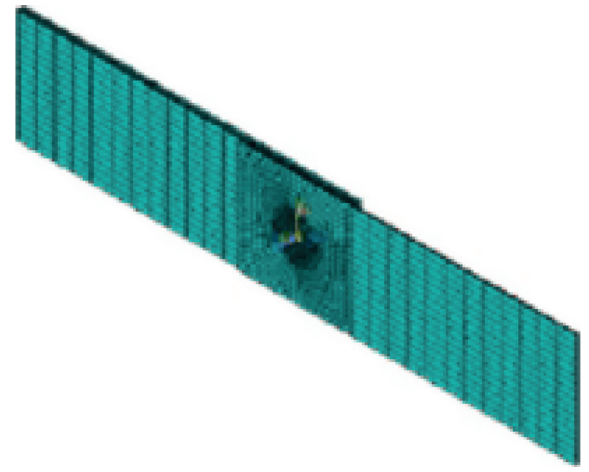

FIgURE 8: Finite element mesh model.

and 90 seconds, respectively, the corresponding temperature distribution cloud pictures are as shown in Figures 10(a) and 10(b).

As shown in Figure 10, the high temperature area gradually expanded over time, and the maximum temperature gradually increased, but the highest temperature remained at $2 / 3$ of the shoulder. The reason was that compared to the edge of the joint, a lot of heat was produced due to larger linear velocity and heat was hard to dissipate small in this area. Located at the centre of heat source, where the temperature was the highest, the galvanized steel sheet DP590 with a high melting point could be more easy to reach the superplastic state, so it had better plastic fluidity, capable of improving the performance of the mixing head and the quality of welded joints.

When the residence time was $60 \mathrm{~s}$, the temperature in most parts of the central area of the mixing head was 


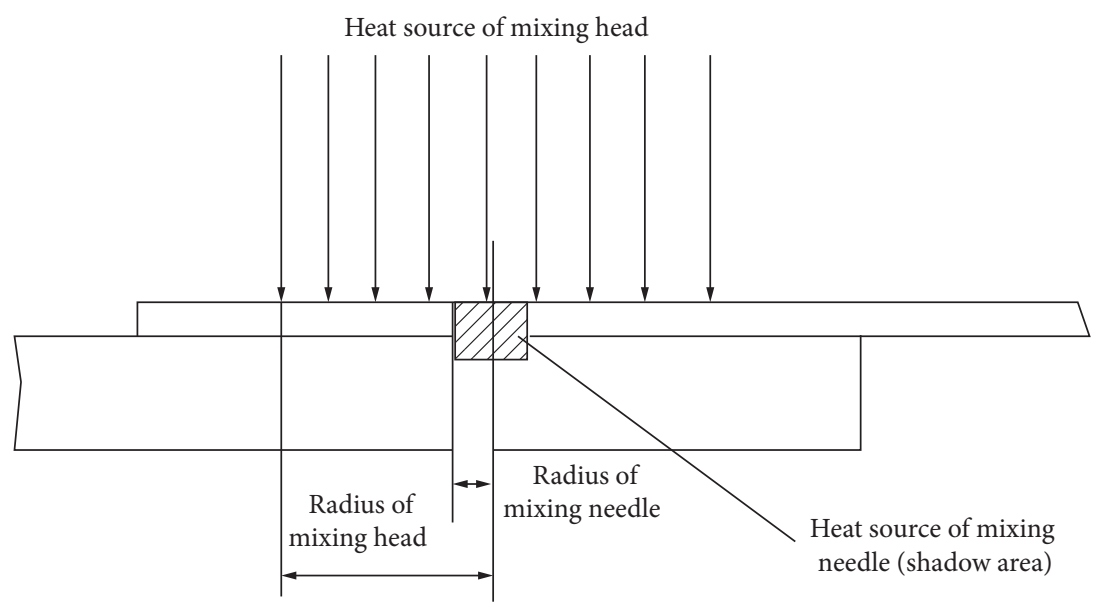

FIgURE 9: The heat source model.
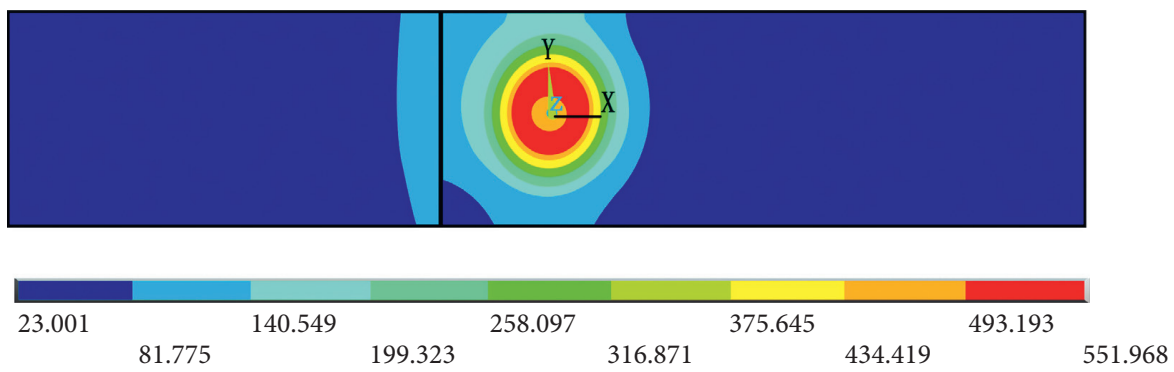

(a)
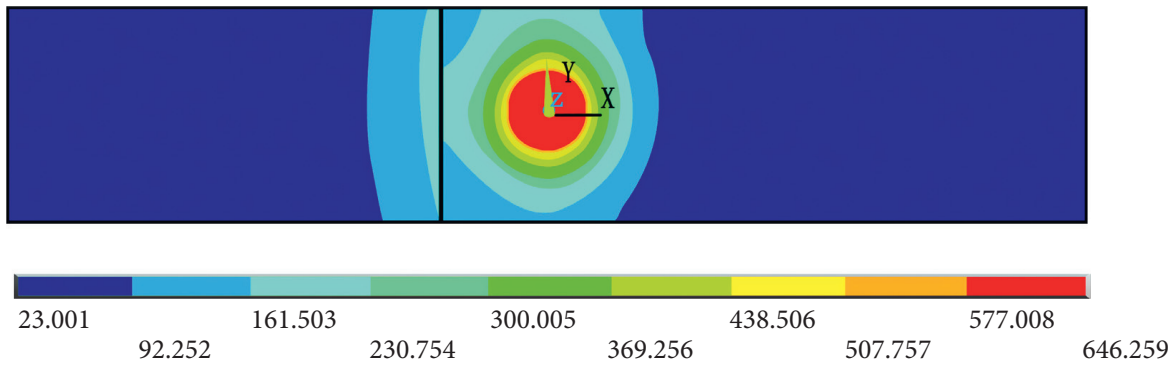

(b)

Figure 10: Cloud pictures of temperature distribution corresponding to different dwell times. (a) $60 \mathrm{~s}$. (b) $90 \mathrm{~s}$.

between $493^{\circ} \mathrm{C}$ and $552^{\circ} \mathrm{C}$, but some parts were still lower than $493^{\circ} \mathrm{C}$ (Figure $10(\mathrm{a})$ ). Uneven temperature distribution and low plasticity made it difficult to form the joint and caused the decrease in shear resistance. When the residence time was $90 \mathrm{~s}$, the temperature in the central area of the mixing head was between $577^{\circ} \mathrm{C}$ and $646^{\circ} \mathrm{C}$ (Figure $10(\mathrm{~b})$ ). The universal superplasticity enabled the readily formation of the joint and improved the shear resistance, which was consistent with the results obtained by the orthogonal test and the shear resistance test.

The temperature distribution cloud image of the transverse section of the welding spot under the rotating speed of $1200 \mathrm{r} /$ min, the pressing depth of $0.3 \mathrm{~mm}$, and the welding time of $90 \mathrm{~s}$ is shown in Figure 11. The red superplastic area was uneven due to the high mixing speed, and the welding joint prepared showed lower performance. The simulation results were consistent with the rotating speed of the test process parameters.

The ANSYS finite element software was used for simulation, which clearly showed the temperature and metal flow state in the welding process as well as their effects on the joint bonding strength. It also revealed the cause of joint fracture.

In order to verify the accuracy of the numerical simulation of the temperature field, a sample was welded under the rotating speed of $1000 \mathrm{r} / \mathrm{min}$, pressing depth of $0.2 \mathrm{~mm}$, and residence time of $90 \mathrm{~s}$ for temperature measuring. The temperature changes of different characteristic points on the sample with time were measured by $\mathrm{Ni} / \mathrm{Cr}-\mathrm{Ni} / \mathrm{Si} \mathrm{K}$ thermocouple [37, 38]. During the test, a small hole with a diameter of $1.5 \mathrm{~mm}$ was drilled through the bottom of the 


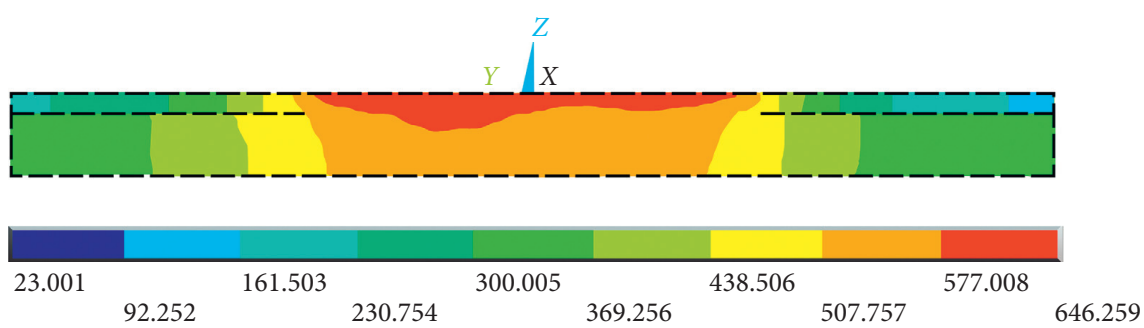

Figure 11: Cloud image of temperature distribution of the cross section in the solder joint centre at $1200 \mathrm{r} / \mathrm{min}, d=0.3 \mathrm{~mm}$, and $t=90 \mathrm{~s}$.

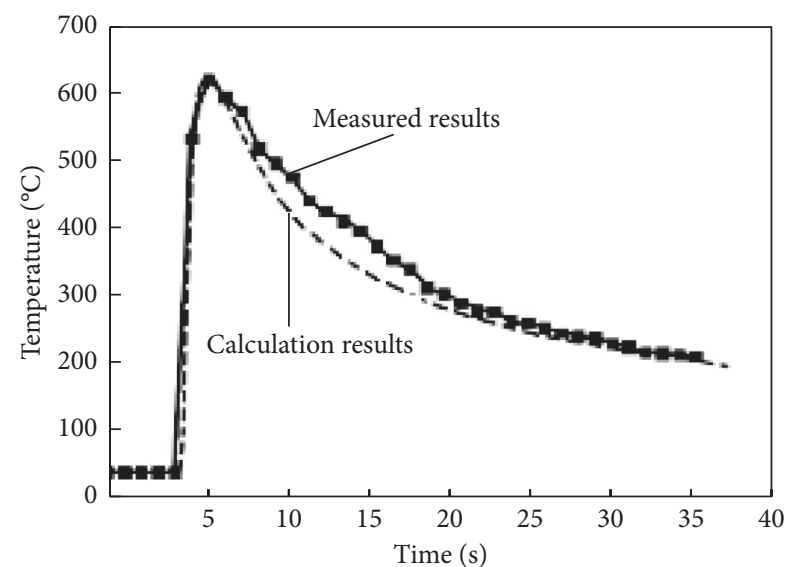

Figure 12: Comparison of measured and simulated results of lap joint temperature.

weldment before one end of the thermocouple was welded into the hole to be tested and on the upper surface of DP590. Then, the small hole was filled and compacted with resin glue. The other end of the thermocouple was connected to a midi LOGGER GL 220 ten-channel temperature recorder [39-41]. During welding, the recorder recorded the timetemperature curve of the measuring point at different rotating speeds. The comparison between the measured temperature and the calculated temperature at the same point is shown in Figure 12.

According to Figure 12, the simulation results were basically consistent with the measured data, which showed the high accuracy of the heat source model, thus verifying the rationality of using ANSYS software to calculate the temperature field of the DP590/6061 friction stir spot welding joint [42]. FSSW was demonstrated to be a solid-state welding technology, which could not only ensure that the metal with a lower melting point did not melt but also render better plastic fluidity to the metal with a higher melting point under the optimal welding parameters, capable of effectively reducing the formation of defects in the fusion welding.

\section{Conclusions}

(1) Under the appropriate process parameters, the addition of aluminium-zinc solder can well wet the welding interface and promote the formation of metallurgical bonding between aluminium and steel. The DP590/6061FSSW joint with solder added has higher shear load than the joint without solder added.

(2) Through the orthogonal test of three factors and three levels, the best process parameters of DP590/ 6061 FSSW lap welding are obtained as follows: the rotating speed of the mixing head is $1000 \mathrm{r} / \mathrm{min}$, the pressing depth of the mixing head is $0.2 \mathrm{~mm}$, and the residence time is $90 \mathrm{~s}$. The joint with high connection strength and the shear load as high as $13.239 \mathrm{kN}$ can be obtained under the optimal process parameters.

(3) The temperature field chart of DP590/6061 FSSW simulated by ANSYS reveals the distribution law of temperature in the process of joint welding. The simulated temperature is basically consistent with the measured temperature, which proves that the heat source model is accurate and the optimized process parameters are reasonable.

(4) According to the numerical simulation of the DP590/6061 FSSW temperature field, the temperature of the joint during the forming process is always lower than the melting point temperature of the base metal, indicating that the FSSW is a solid-phase connection technology that can effectively lower the occurrence rate of some common welding defects during the fusion welding process.

\section{Data Availability}

The data used to support this study are available from the corresponding author.

\section{Conflicts of Interest}

The authors declare that there are no conflicts of interest regarding the publication of this paper.

\section{Acknowledgments}

This work was supported by the Anhui Province University Natural Science Key Research Project in 2017 (grant no. KJ2017A750).

\section{References}

[1] R. S. Mishra and Z. Y. Ma, "Friction stir welding and processing," Materials Science and Engineering R: Reports, vol. 50, no. 1-2, pp. 1-78, 2005. 
[2] Y. Uematsu, K. Tokaji, Y. Tozaki, T. Kurita, and S. Murata, "Effect of re-filling probe hole on tensile failure and fatigue behaviour of friction stir spot welded joints in Al-Mg-Si alloy," International Journal of Fatigue, vol. 30, no. 10-11, pp. 1956-1966, 2008.

[3] L. Zhang, M. Liu, J. Jiang et al., "The development of welding of aluminum alloy and steel," Aerospace Manufacturing Technology, vol. 2, pp. 5-9, 2013.

[4] D. Zhou, Y. Liu, N. Li et al., "Effect of Sn-5\%Zr powder addition on microstructure and mechanical property of steel/ Al laser welding," Chinese Journal of Lasers, vol. 42, no. 5, pp. 95-103, 2015.

[5] S. Yu, K. Jiang, and D. Fan, “5056 aluminum alloy and coated steel overlapped fusion welding-brazing by laser with preset filler powder," Journal of Mechanical Engineering, vol. 50, no. 12, pp. 83-88, 2014.

[6] Z. Lei, G. Qin, S. Lin et al., "Fusion-brazing joining for dissimilar metals between 5A02 aluminium alloy and zinccoated steel based on laser-MIG hybrid welding," Journal of Mechanical Engineering, vol. 45, no. 3, pp. 94-98, 2009.

[7] X. Zhao and R. Xiao, "Fluxless joining between aluminum alloy and galvanized steel by fiber laser fusion welding-brazing with filler power," Chinese Journal of Lasers, vol. 39, no. 4, pp. 74-78, 2012.

[8] D. Zhang, S. Gao, H. Gao, and Z. Jianzhe, "Wire feeding laser brazing and fusion for Al-Fe dissimilar metal," Laser \& Optoelectronics Progress, vol. 48, no. 6, pp. 91-98, 2011.

[9] S. A. Hussein, S. Thiru, R. Izamshah, and A. S. Md Tahir, "Unstable temperature distribution in friction stir welding," Advances in Materials Science and Engineering, vol. 2014, Article ID 980636, 8 pages, 2014.

[10] B. T. Gibson, D. H. Lammlein, T. J. Prater et al., "Friction stir welding: process, automation, and control," Journal of Manufacturing Processes, vol. 16, no. 1, pp. 56-73, 2014.

[11] L. E. Murr, "A review of FSW research on dissimilar metal and alloy systems," Journal of Materials Engineering and Performance, vol. 19, no. 8, pp. 1071-1089, 2010.

[12] M. Dehghani, A. Amadeh, and S. A. A. Akbari Mousavi, "Investigations on the effects of friction stir welding parameters on intermetallic and defect formation in joining aluminum alloy to mild steel," Materials \& Design, vol. 49, pp. 433-441, 2013.

[13] Z. Ruxing, L. Zhou, Y. Zhao et al., "Study on the process and joint properties of aluminum steel hybrid metal embedded FSW," Hot Working Technology, vol. 46, no. 11, pp. 211-213, 2017.

[14] C. Rajendran, K. Srinivasan, V. Balasubramanian, H. Balaji, and P. Selvaraj, "Effect of tool tilt angle on strength and microstructural characteristics of friction stir welded lap joints of AA2014-T6 aluminum alloy," Transactions of Nonferrous Metals Society of China, vol. 29, no. 9, pp. 1824-1835, 2019.

[15] C. Rajendran, K. Srinivasan, V. Balasubramanian, H. Balaji, and P. Selvaraj, "Effect of post weld heat treatment on strength and microstructure of friction stir welded lap joints of AA2014-T6 aluminum alloy," Metal Science and Heat Treatment, vol. 61, no. 5-6, pp. 305-310, 2019.

[16] C. Rajendran, K. Srinivasan, V. Balasubramanian, H. Balaji, and P. Selvaraj, "Identifying combination of friction stir welding parameters to maximize strength of lap joints of AA2014-T6 aluminum alloy," Archives of Mechanical Technology and Materials, vol. 37, no. 1, pp. 6-21, 2017.

[17] X. Wang, Y. Zhang, Z. Zhang et al., "Welding analyses of friction stir spot welding without keyhole between aluminum alloy and zinc-coated steel," Transactions of the China Welding Institution, vol. 36, no. 1, pp. 1-4, 2015.

[18] Y. X. Huang, B. Han, Y. Tian et al., "New technique of filling friction stir welding," Science and Technology of Welding and Joining, vol. 16, no. 6, pp. 497-501, 2011.

[19] H.-S. Mun and S.-I. Seo, "Welding strain analysis of friction stir-welded aluminum alloy structures using inherent strainbased equivalent loads," Journal of Mechanical Science and Technology, vol. 27, no. 9, pp. 2775-2782, 2013.

[20] D. Jacquin, B. de Meester, A. Simar, D. Deloison, F. Montheillet, and C. Desrayaud, "A simple eulerian thermomechanical modeling of friction stir welding," Journal of Materials Processing Technology, vol. 211, no. 1, pp. 57-65, 2011.

[21] J. L. Perez-Castellanos and A. Rusinek, "Temperature increase associated with plastic deformation under dynamic compression: application to aluminium alloy AL 6082," Journal of Theoretical and Applied Mechanics, vol. 50, no. 2, pp. 377-398, 2012.

[22] D. Trimble, J. Monaghan, and G. E. O’Donnell, "Force generation during friction stir welding of AA2024-T3," CIRP Annals, vol. 61, no. 1, pp. 9-12, 2012.

[23] Y. J. Chao, S. Liu, and C. H. Chien, "Friction stir welding of al 6061-T6 thick plates: Part II-numerical modeling of the thermal and heat transfer phenomena," Journal of the Chinese Institute of Engineers, vol. 31, no. 5, pp. 769-779, 2008.

[24] B. M. Tweedy, C. A. Widener, J. D. Merry, J. M. Brown, and D. A. Burford, "Factors affecting the properties of swept friction stir spot welds," in Proceedings of the SAE SP World Congress Technical Paper 2196, Detroit, MI, USA, April 2008.

[25] A. Bachmaier, M. Hafok, and R. Pippan, "Rate independent and rate dependent structural evolution during severe plastic deformation," Materials Transactions, vol. 51, no. 1, pp. 8-13, 2010.

[26] X. Liu, Y. Yu, S. Yang, and H. Liu, "A modified analytical heat source model for numerical simulation of temperature field in friction stir welding," Advances in Materials Science and Engineering, vol. 2020, Article ID 4639382, 16 pages, 2020.

[27] Z. H. Zhang, W. Y. Li, J. L. Li, and Y. J. Chao, "Effective predictions of ultimate tensile strength, peak temperature and grain size of friction stir welded AA2024 alloy joints," The International Journal of Advanced Manufacturing Technology, vol. 73, no. 9-12, pp. 1213-1218, 2014.

[28] B. Abnar, M. Kazeminezhad, and A. H. Kokabi, "Effects of heat input in friction stir welding on microstructure and mechanical properties of AA3003-H18 plates," Transactions of Nonferrous Metals Society of China, vol. 25, no. 7, pp. 21472155, 2015.

[29] C. Gao, Z. Zhu, J. Han, and H. Li, "Correlation of microstructure and mechanical properties in friction stir welded 2198-T8 Al-Li alloy," Materials Science and Engineering: A, vol. 639, pp. 489-499, 2015.

[30] H. Yu and Z. Hu, "Investigation of interfacial microstructure and mechanical properties for DP590 steel/7075 aluminum dissimilar materials friction stir lap welding joints," Journal of Mechanical Engineering, vol. 56, no. 4, pp. 1-8, 2020.

[31] Z. Zhang and J. T. Chen, "Computational investigations on reliable finite element-based thermomechanical-coupled simulations of friction stir welding," The International Journal of Advanced Manufacturing Technology, vol. 60, no. 12, pp. 959-975, 2012.

[32] F. Al-Badour, N. Merah, A. Shuaib, and A. Bazoune, "Coupled eulerian lagrangian finite element modeling of friction stir 
welding processes," Journal of Materials Processing Technology, vol. 213, no. 8, pp. 1433-1439, 2013.

[33] G. Chen, Z. Feng, Y. Zhu, and Q. Shi, "An alternative frictional boundary condition for computational fluid dynamics simulation of friction stir welding," Journal of Materials Engineering and Performance, vol. 25, no. 9, pp. 4016-4023, 2016.

[34] E. Feulvarch, J.-C. Roux, and J.-M. Bergheau, "A simple and robust moving mesh technique for the finite element simulation of friction stir welding," Journal of Computational and Applied Mathematics, vol. 246, pp. 269-277, 2013.

[35] N. Dialami, M. Chiumenti, M. Cervera, and C. Agelet de Saracibar, "An apropos kinematic framework for the numerical modeling of friction stir welding," Computers \& Structures, vol. 117, pp. 48-57, 2013.

[36] A. Aziz, "A similarity solution for laminar thermal boundary layer over a flat plate with a convective surface boundary condition," Communications in Nonlinear Science and Numerical Simulation, vol. 14, no. 4, pp. 1064-1068, 2009.

[37] J. Hilgert, H. N. B. Schmidt, J. F. dos Santos, and N. Huber, "Thermal models for bobbin tool friction stir welding," Journal of Materials Processing Technology, vol. 211, no. 2, pp. 197-204, 2011.

[38] Y. H. Yau, A. Hussain, R. K. Lalwani, H. K. Chan, and N. Hakimi, "Temperature distribution study during the friction stir welding process of Al2024-T3 aluminum alloy," International Journal of Minerals, Metallurgy, and Materials, vol. 20, no. 8, pp. 779-787, 2013.

[39] V. S. Gadakh and K. Adepu, "Heat generation model for taper cylindrical pin profile in FSW," Journal of Materials Research and Technology, vol. 2, no. 4, pp. 370-375, 2013.

[40] H. Bisadi, S. Rasaee, and M. Farahmand, "Thermal analysis of plunge stage in friction stir welding: simulation and experiment," International Journal of Basic Sciences and Applied Research, vol. 2, no. 11, pp. 968-975, 2013.

[41] Z. Zhang and Q. Wu, "Analytical and numerical studies of fatigue stresses in friction stir welding," The International Journal of Advanced Manufacturing Technology, vol. 78, no. 9-12, pp. 1371-1380, 2015.

[42] H.-J. Zhang, H.-J. Liu, and L. Yu, "Thermal modeling of underwater friction stir welding of high strength aluminum alloy," Transactions of Nonferrous Metals Society of China, vol. 23, no. 4, pp. 1114-1122, 2013. 